cheek and a little fulness to the pulse for a short time after the patient wakes; but, as a rule, they cease when the coma ceases, and coma is never much prolonged in simple epilepsy. Usually the patient is headachy and exhausted, listless and stunned, moody and irritable, until a night's rest has enabled him to recover the balance of his shaken nervous system. The jaded countenance also tells plainly of the past struggle, even though it may present none of those numerous and minute dots of ecchymosis about the eyelids and upon the forehead which are such unequivocal signs of a severe attack of epilepsy.

As time goes on, the mental faculties recover more and more imperfectly, and more and more tardily, and at last their habitual state may be one of pitiful fatuity from which no single ray of the Divine principle beams forth. Or the moodi. ness and irritability which often follow attacks may become more and more marked, until at last they merge into attacks of downright mania. Or symptoms of paralysis may make their appearance. Or death may happen in a fit, or shortly afterwards. The natural tendency of epilepsy is assuredly towards dementia; and dementia is the frequent doom of the epileptic, if his disorder be unchecked and life prolonged sufficiently; but at the same time it is possible for an epileptic to live many years, and to have many fits, without losing the powers which are necessary to render him an agreeable and serviceable member of society. When death happens, it appears to be, most generally, from exhaustion in the period of prostration immediately following the paroxysm.

But the symptoms of epilepsy are not always so startling as have been represented, and in some instances they may be so softened down as to be recognised with difficulty.

In the slightest form of the malady, the patient pauses suddenly in the midst of anything he may happen to be doing or saying at the time, his countenance becomes pale and blank, his lungs cease to play, and, after a moment of absence or giddiness, he is himself again. His memory has kept no record of this sad passage in his history, and if it had escaped the notice of others he might remain in happy ignorance of it. Or, in addition to these symptoms, a lurid flush may succeed to the paleness of the countenance, the veins of the neck and forehead may start out in prominent relief, the face may turn slightly towards one of the shoulders, and there may be some convul. sive twitching in the face and neck and arms. In such a case there is no scream or cry, no fall, no bitten tongue, no foam at the mouth, and at most there is only some obscure gurgling in the throat, some staggering, and some slight moistening of the lips with saliva. In such a case the convulsive movements are very" partial, rarely extending beyond the face, neck, or arms, but in some fow instances the whole frame may be agitated by one or two violent convulsive shocks. This state of giddiness and absence and partial spasm may be followed by fatigue, loss of memory, confusion of thought, depression of spirits, or irritability of temper, and at times it may end in drowsiness or actual sleep; but usually recovery is almost instantaneous. At the same time there is reason to believe that dementia is a more likely as well as a more speedy consequence in this, le petit mal, than in ordinary epilepsy, le grand mal.

In some of these cases, moreover, it would seem not only that the patient does not cry, or fall, or suffer from general convulsion, but that the state of intellectual eclipse-the most characteristic symptom of epilepsy-is far from complete. Esquirol says, "il est des accès dans lesquels on n'observe pas la perte de connaisance;" and M. Herpin directs particular attention to these cases. Cases like these are common enough in certain chronic diseases of the brain, as meningitis or tumour but in simple epilepsy they are by no means common, if other proof be wanting than the mere assertion of the patient. have met with four such cases, and have put them on record in various places.

The morbid appearances after death from simple epilepsy are necessarily very obscure, if the case have really been one of simple epilepsy, and not one of epileptiform convulsion connected with some special disease. In cases fatal during the fit the brain has been found to be congested; but this appearance is clearly owing to the mode of death, and it is allowed to be so. In cases, again, where epilepsy has been complicated with insanity, the brain or its membranes may present various signs of inflammation, or of changes more or less akin to inflamma. tion; but these signs are clearly referable to the mental disorder, and for no other reason than this-that they are as common, or more common, in insanity without epilepsy. In other cases there are signs of degeneracy, such as pallor of the grey matter, softening, induration, atrophy, dropsical effusion; but these are the very signs which belong to the demented state. It is this very fact, however, which furnishes some grounds for supposing that signs of this character may have something to do with epilepsy. It does so, because the demented state is intimately connected with convulsive disorder; for if a demented person be not epileptic, he is almost sure to be affected with palsied shakings, or cramps, or spasms, in one form or another. In other cases, again, the skull may be thicker and heavier than usual, and the several internal projections - as the clinoid processes-may be considerably developed, or various parts of the dura mater may be converted into bone. Indeed, there are no constant changes in the brain proper or in its coverings-not even that change in the pituitary body of which so much has been said by Wenzel; for, writing of it, Rokitansky says that he has " frequently failed to discover it in those who had notorionsly suffered from epilepsy and convulsions," and that he has "met with it in others who were thoroughly healthy." It is in the medulla oblongata, indeed, that we alone meet with any appearances after death which can be regarded as constant. In early cases of epilepsy, it is true, we may fail to find anything characteristic even here; but in confirmed cases the medulla oblongata is often harder than natural, from the interstitial deposit of a minutely granular albuminous matter, or else softened, swollen, and presenting evident signs of fatty degeneration. Professor Van der Kolk, who was the first to detect these appearances, has also detected some marked changes in the bloodvessels of the part, and to these changes he directs particular attention. He has examined fifteen epileptics after death, and in them all the posterior half of the medulla oblongata, on making a transverse section, was found to be redder and more hyperæmic than it ought to be; and this was the case whether death happened in an attack or not. On more minute examination, he found the bloodvessels dilated to thrice their natural dimensions, and their walls much thickened. And on comparing the medulla oblongata of several epileptics who bit their tongue, with the medulla oblongata of other epileptics who did not bite their tongue, he found (what is a very curious fact) that the capillaries were especially dilated in the course of the hypoglossus and the corpus olivare in the former case, where the tongue was bitten in the fit, and in the course of the roots of the vagus in the latter case, where the tongue was not bitten in the fit. These discoveries of Professor Van der Kolk are the most recent as well as the most important facts in con. nexion with the post-mortem appearances of epilepsy.

\section{ON THE ATHEROMATOUS EXPRESSION.}

\section{By GEORGE D. GIBB, M.D., M.A., M.R.C.P.,} PHXSICTAN TO THE ST. PANCRAS ROYAL DISPENSARX.

THERE is a certain class of diseases of which examples here and there present themselves to our notice amongst individuals who are constantly in the habit of mixing in the daily bustle of life, enjoying apparently a fair share of health, and whose appearance to many, both in our profession and out of it, is that of extremely good health. Such persons, if they go to assure their lives, will probably meet with a superficial or perhaps formal examination, because of their healthy appearance; and yet their lives are doubtful ones. The antecedent history may be a good one; nevertheless, owing to changes going on in the system at large, from the influence of fat and its numerous compounds, the invariable result of saccharine conversion in the economy, there is the development of a state of things which, although liable to detection by careful and minute phy. sical examination, is more especially made known to the acute observer by what I purpose calling the "atheromatous expression." This peculiar expression has been the subject of carefuI study with me for a number of years, and is daily forcing itself upon my attention during the pursuance of my avocations. If riding in an omnibus, if a passenger on one of the river steamboats, or if in railway carriage, some one or more individuals with the atheromatous expression may be present. Perhaps a person with it is sitting opposite to me in an omnibus, and he thus affords me an excellent opportunity of studying every lineament of his features, and further confirming the correctness of my own views and conclusions. In the many thousand cases of disease constantly coming under my notice in the im. 
mense field of London hospital practice, which it is my especial privilege to make use of, a tolerable number, in both sexes, present themselves with it. In assemblages of persons, whether public or private, it is quite possible to point out those who possess it.

Such statements as the foregoing might give cause for uneasiness and alarm; this, however, will be removed when it is mentioned that persons thus featured, with quiet, care, moderation in living, the avoidance of excitement and of the special causes which help to further its development, may go on smoothly and comfortably till a ripe old age is reached. But, in accordance with our advancing knowledge, and the accuracy of our powers of discrimination of disease by the countenance and general physique-powers eminently possessed by those amongst us whose development of the perceptive faculties is strong, and whose organ of individuality is large, - it is requisite that the attention of the profession generally should be drawn to such an important subject as tho present, as a discovery or announcement quite in accordance with the advancing spirit of the age we live in.

The atheromatous expression is an indication presented by the countenance of the changes which are either about to commence or are aiready going on within, and mainly affecting the condition of the blood primarily, and of the vessels which carry it secondarily. Without entering into the most important question now, of how the blood thus becomes diseased, it will be quite sufficient for my purpose to state that atheromatous deposition in the coats of the bloodvessels is the consequence of the former. This latter may be pronounced in the larger trunks proceeding direct from the heart, and almost invariably have the cerebral blood vessels associated in a similar condition; or else the arteries at a distance may be involved, when the expression is modified, as I shall presently show, into a variety or subdivision which I shall denominate the calcareo-atheromatous expression. Without stopping to inquire into the pathological peculiarities indicated in the foregoing observations, as they are probably familiar to most observers, I will mention that life is jeopardized by the risk of cerebral hæmorrhage or intense congestion, by fatal cardiac syncope, or by aneurismal disease in distant parts. There may be inherent disease that helps to develop this state of things, for it is observed sometimes in gout, rheumatism, disease of the kidneys, cancer, polysarcia, \&c. Persons with this expression get through attacks of other diseases very badly, on account of the state of weakuess and prostration which it necessarily engenders. The condition of the blood vessels, whether it be deposits of atheroma or of calcified or phosphatic matter, is never the result of any inflammatory process, but is unquestionably due to simple metamorphosis, through the agency of the blood.

It is, perhaps, not an easy matter to recognise the marked features of the atheromatous expression by almost any descrip. tion that may be given, as the idea of it is very difficult to convey in words; the opportunity of having it pointed out would be preferable, and worth a hundred descriptions. Those, however, who are experienced in the facial physiognomy of disease may be enabled, perhaps, to recognise what is meant by the following observations:-

There will be noticed a peculiar greasy appeararce of the face, especially about the prominent part of the cheeks and end of the nose. The lips have a fulness which is unmistakable; the ala of each nostril is smooth and rounded; whilst the features generally seem plump and well developed, because of the subcutaneous areolar structures being well supplied with the adipose element. There is often a double chin, of varying dimensions. The skin of the face may be reddish, or perhaps pinkish, with the small vessels on its surface injected here and there with blood of a bright-red colour, which extends in many cases to the tips and lobuli of the ears. The character of the injection is sometimes peculiar, and runs in irregular streaks, with little stellæ here and there. The eyes are very bright, occasionally watery (not from drink), and of a fatty lustre, especially about the ocular conjunctivæ. Once in a while, a well-marked arcus adiposus or arous senilis will be seen, which may be a simple arcus or a complete annulus. Sometimes the eyes are seen to be prominent, with the surrounding tissues filled ont, as it were, by fatty deposits. The general com. plexion is heightened, and there is an air of ease and contentment about the individual as if the cares of life sat lightly upon him.

Although this expression is not at all uncommon in the aged it is observed in a large number in the prime of life, and even in those who are much younger. I can call to mind a gentleman with it, who is not more than twenty, and in whom it will become further developed in a few years. The appearance of the nose and cheeks alone determines me in try opinion. He has no arcus. This $I$ may observe, however, is not abso. lutely essential; but its presence, taken with othet pectuliarities, is corroborative of the expression, and renders it the more striking and manifest. But, as a rule, which I have worked out by watching a large number of persons thus featured, life is extremely uncertain, and sooner or later becomes the forfeit, to the astonishment of their friends, who had hitherto looked upon them as models of health from their complexion and general appearance. Yet, as I observed before, individuals: whose daily course of life is regular and smooth, without excitement, may go on and live for years, and reach, perhaps, a comfortable age, with the lining membrane of their bIoodvessels in a state of atheromatous disease. Let any secret source of annoyance and worry arise, however, to arresis the even tenour of their way, and if they do not experience a rupture of some minute cerebral bloodvessels, they may become the subject of other diseases in which the destructive saccha. rine conversion plays an important part, in depositing fat in the tissues of important organs. Pathologists at the present, day might explain this saccharine conversion in the economy. by the chemical changes which the amyloid substance or hepa. tine prevalent in almost all the tissues undergoes. But for some years before the latter was discovered, I had set down the changes in my own mind as due to those which the sugar undergoes, no matter what its source might be, or how formed.

There are certain expressions and appearances of the visage. which must not be mistaken for that under consideration, as the florid redness, with perhaps natural roughness of the cuticle, has arisen from exposure to the vicissitudes of temperature and of climate. Such is visible in seamen, captains of ships, and many others who possess a weather-beaten countenance, a peculiarity which is altogether different. Other persons, again, possess a florid complexion without having suffered exposture, and who are free from disease; and discrimination is necessary to distinguish between these healthy states and that derived from atheroma. The appearances due to the lymphatic temperament are also liable to be mistaken for it.

The calcareo-atheromatous expression is a variety or subdivision of the other, and may be known by the following differences: the general features of the face are the same, but there is a whiteness or pallor of the countenance which depends upon another cause. The eye is fatty, and a distinct kluishwhite annulus, or ring, surrounds the entire margins of the cornea. This ring may be narrow, very narrow, perhaps, and so will escape observation. A most striking example of is was lately under Dr. Farre's care in the medical wards of St. Bartholomew's hospital. This pallor (which varies in a mixture of the two expressions) and this bluish-white ring round the cornea indicate the extensive deposition of calcareous or earthy matter in the distal bloodvessels, - that is, in the major vessels of the extremities: the radial, the ulnar, and the tibial, and occasionally the femoral and the axillary, in both sides of the body. They can readily be felt, during life, as hard and firm tubes under the finger. Mr. Canton kindly showed me a most exquisite representation of the bluish-white annulus in both eyes of a person in good health, in whom $I$ at once recognised the calcareo-atheromatous expression; and although $I$ have not as yet had an opportunity of examining his bloodvessels, I feel persuaded that they are slowly becoming hard cylinders from calcareous deposits in those of the extremities. The radial at the wrist felt hard under the finger.

Since then (Feb. 22nd) I was requested by my colleague, Dr. Bealey, to see a woman, aged sixty, the subject of uterine hæmorrhage off and on for the last eight months, the catamenia having ceased for twenty years. This depends upon cancer of the uterus, which is felt hard and enlarged in the vagina. All the arteries of the body are quite hard, like twigs beneath the skin. When using any exertion, or forcibly coughing, sudden swellings used to appear on the arms along the course of the vessels; about two inches long; they would become red, then purple, and firally yellow and green, like the remains of a bruise, until their absorption was complete. A congestive swelling in the right groin used always to precede the catamenia, and would then vanish. Has had cough every winter for the last five years, and is now much emaciated, with a white face-in fact, the calcareous expression simply, with an entire absence of atheroma. The heart is not much diseased; its action is strong, giving to the pulse a hard and firm character, beats 104. Her mother was lame for twenty-five years from rheumatism, and lived to seventy-three years, and her father to sixty-six. There is no bluish annulus in this patient, but there is commencement of deposit at the upper part of the cornea in one eye. This case is a practical verification of my 
remark, that the heart and all the bloodvessels are not simultaneously extensively diseased; for here we have all the latter affected, and the former triflingly so, or perhaps not at all organically involved, beyond calcification (not atheromatous degeneration) of the coronary arteries.

In my work on "Diseases of the Throat and Windpipe," just published, I have further dwelt upon this subject, together with the relationship which subsists between the changes in the cartilages of the larynx and in the arterial blood vessels, but will refrain from entering into it here. I may observe, however, that as a rule atheromatous conversions are the commonest, and mostly involve the heart; whilst, on the other hand, calcification of the bloodvessels is more rare, and leaves the heart comparatively uninvolved. A mixture of the two is still less frequently to be seen; but a good example in point is the patient of Dr. Farre, already alluded to.

Among six hundred autopsies performed by myself, together with a very much larger number undertaken by others at which I have been present, the verification of the correctness of my views, in relation to the pathological changes giving rise to these three forms of expression, has been largely proved in those in stances in which the latter were recognised during life; and although it is tolerably frequent, and rather common in some classes of individuals, there are others, again, who do not and never will possess it.

In my description of the atheromatous expression, the features will not always come up to what I have stated, but will present various modifications, no doubt influenced by the circumstances and condition of the possessors. There may be an absence of the fatty look in some, yet the features have the peculiar puffiness which resembles the brawny œdema of the arm, for instance, in cancer. But it is a most curious and really wonderful fact, that the intellectual vigour of the mind, in its perfection and purity, remains unchanged, and yet the body (no matter if the expression is present even before thirty) is in the condition of advanced senility; so that an individual who may be affected in the manner described at forty, and who should be enabled to reach sixty or even seventy, has his corporeal capacity relatively equal to the ages of eighty and ninety.

It is not my purpose to go into the question of treatment at all, but two or three things may be mentioned in concluding this paper. Persons thus affected should avoid malt liquor, and rather snbstitute light wines and pure spirit. Substances likely to turn into fat and atheroma should be eschewed. Chloroform should not be given when operations are required Above all, a proper estimation of such lives should be taken into account by insurance companies. And lastly, in describing cases of disease, the use of the particular term of expression of the conntenance will be found most convenient.

On another occasion, I may enter somewhat more fully into the details of this important subject; for the present, it is my desire only to introduce it to the notice of the profession.

Portman-street, Portman-square, May, 1860.

REPORT OF A CASE OF

\section{RETAINED MENSES FROM IMPERFORATE OS UTERI;}

OPERATION; DEATH.

By I. BAKER BROWN, F.R.C.S. (Examir.), SENIOR SURGEON TO "THE LONDON HOMrE."

S. L - aged sixteen, the daughter of a monthly nurse, was brought to me at "The London Home" by her mother. She had never menstruated. About every month she suffered great pain in the abdomen and back, lasting for a period vary. ing from a few hours to three days. This was accompanied by all the usual symptoms of menstruation, without, however, there being any external appearance. The pain was described as being so severe, as to cause her to roll about the floor in agony. She had all the usual marks of confirmed puberty, was tall and well made.

On making an examination, per vaginam, I found it terminate superiorly in a perfect cul-de-sac. The neck of the uterus conld be felt in its normal position; but no os nteri was distinguishable. The lips of the os could be obscurely made out,

covered, as it were, with the lining membrane of the vagina. By examination through the rectum, the uterus could be felt increased in size, and presenting to the taxis a sense of fluctuation. It was evident that the case was one of retained menses from congenital closure of the os uteri. The general health was becoming a good deal affected. I explained to the mother that the closure of the os uteri must have existed from birth, and that nothing but an operation would be of any service.

She was, therefore, admitted into "The London Home" on March 5th, and on the 8th of the same month she was subjected to the influence of chloroform, and further examined by Dr. Hall Davis and Mr. Philip Harper, who both agreed with me as to the nature of the case and the neces. sity of an operation. I therefore proceeded to operate in the presence of those gentlemen and Dr. Menzies, Messrs. Ince, Ince, jun., Andrews (all of Pimlico), Spencer, and Dr. Giles. She was placed in the lithotomy position, and I passed my finger into the vagina until the end of it was in contact with the obscurely felt lips of the os uteri. I now introduced a pair of sharp-pointed straight scissors along the finger to the obstruction, and gently pressed them through it, without opening them. It required very little force to penetrate the membrane. On withdrawing them, a quantity of thick fluid, of treacly consistence, but of the colour of red-currant jelly, immediately flowed out. I now passed one finger into the rectum, whilst gentle counter-pressure was made on the abdomen, and thus a quantity of the fluid flowed out (about five or six ounces, subsequently increased to nearly three-quarters of a pint). The vagina was syringed out with warm water, a napkin and binder put on, and she was placed in bed. When she had recovered from the chloroform, one grain of opium was given to her, which was to be repeated every six hours. There was not the least hæmorrhage.

The following account of her progress is from the notes of Mr. Wratislaw, the visiting surgeon in charge:-

March 9th. - Nine A.M. : Has had a good night, and felt so well this morning that she was found sitting up in bed doing some crotchet work. The thick fluid had continued to flow during the night, and the nurse had collected about six ounces of it. It had now changed to a brighter red, having the appearance of natural menstruation. -Nine P.M.: Slight sickness had come on in the course of the day, and there was some un. easiness with tenderness in the epigastrium. The countenance was swarthy; tougue coated. Ordered hot linseed poultices over the abdomen; and to take three grains of grey powder with five grains of Dover's powder at bedtime, and effervescents every three hours.

10th. - At three A.M., as she had not slept and was very restless, a grain of opium was administered as a suppository. Not being relieved, another grain of opium was given by the mouth. This produced no effect, and at nine A.M. vomiting of dark bile came on, and was very frequent. The pain in the epigastrium was severe; pulse 120; tongue foul; bowels have not acted. She lies upon her back, with the legs stretched out and extended. Turpentine epithems were applied over the abdomen, and a dose of castor oil was given. This produced dark bilious motions, but the sickness continued. In the course of the day tympanitis came on, and the tongue became very dry; pulse 130, very weak. She became so prostrate and sinking in the evening, that frequent doses of ether were administered.

11th.- Has had a bad night; the vomiting of the same bilious matter is incessant; pulse 140 ; tympanitis and tenderness of the epigastrium; tongue dry and brown, except at the edges, where it is red. A grain of calomel was given, and a blister applied to the abdomen. The sickness ceased after this, but she continued to sink, and died soon after four P.M., continuing perfectly sensible to the last.

The following account of the post-mortem appearances was drawn up by Mr. Leggatt, of William-street, Lowndes-square, her usual medical attendant, and Mr. Philip Harper :-

Examination tuenty-six hours after death.-On opening the abdomen, there was not any appearance of general peritonitis; but on examining that portion of the intestines which was in contact with the uterus, there was evidence of local inflammation, plastic lymph having been recently thrown out. The uterus was large, and had recovered from its retroflexed condition. On being removed from the body, it was laid open through the cervix. Its lining membrane was very vaseular and injected, from the long contact of the menstrual fluid. The puncture had been made into the os, and its surrounding edges presented a dark and ecchymosed appearance. The ovaries were enlarged, softened, and granular in appearance and feeling. Liver quito healthy. 